\title{
A expansão do Instituto Federal de Santa Catarina numa perspectiva de política social
}

Thiago Teixeira ${ }^{1 *}$, Kelly Gianezini ${ }^{2}$

\author{
1Universidade do Extremo Sul \\ Catarinense (UNESC), Mestre pelo \\ Programa de Pós-Graduação em \\ Desenvolvimento Socioeconômico \\ (PPGDS) da UNESC \\ https://orcid.org/0000-0003-2957- \\ $\underline{5302}$ \\ ${ }^{2}$ Docente Permanente do Programa de \\ Pós-graduação em Desenvolvimento \\ Socioeconômico (PPGDS) da UNESC, \\ Doutora em Educação pela UFRGS \\ com estágio de doutoramento na \\ Universidade da Califórnia, Los \\ Angeles (UCLA). \\ http://orcid.org/0000-0002-8250- \\ $\underline{088 X}$
}

*Autor correspondente: thiago.teixeira@ifsc.edu.br

\begin{abstract}
Resumo:
Este artigo versa sobre a expansão dos Institutos Federais de Educação, Ciência e Tecnologia, com foco no processo ocorrido no Instituto Federal de Santa Catarina. 0 propósito do trabalho é a compreensão do processo de expansão do Instituto Federal de Santa Catarina em uma perspectiva de política social, fazendo um levantamento bibliográfico sobre política pública, e por fim, estabelecendo uma relação com a expansão e os objetivos do Instituto Federal de Educação, Ciência e Tecnologia de Santa Catarina. As políticas públicas, independente de serem econômicas, fiscais, educacionais ou mesmo com outro foco, devem refletir no social, servindo como ferramenta que estruture a sociedade e torne melhor a vida das pessoas. Desse modo, observa-se que a expansão por meio da interiorização, a ampliação da oferta de educação profissional, a preocupação com o arranjo produtivo local, e a formação focada no cidadão, são características da expansão da Rede Federal de Educação Profissional e Tecnológica que podem ser associadas com as políticas de cunho social, o que permite concluir que a conexão existente entre a comunidade na qual o campus está instalado, o arranjo produtivo local e o próprio Instituto, é condição essencial para a compreensão da política pública presente neste processo de expansão, bem como para o alcance de seus objetivos.
\end{abstract}

Palavras-chave: Instituto Federal. Expansão. Política Pública. Desenvolvimento Socioeconômico.

REVISTA MACAMBIRA

Instituto Federal de Educação, Ciência e Tecnologia Baiano, campus Serrinha. Estrada Vicinal de Aparecida, s/n, Bairro Aparecida, Serrinha (Ba), CEP: 48700-000, sala 01, prédio acadêmico. 


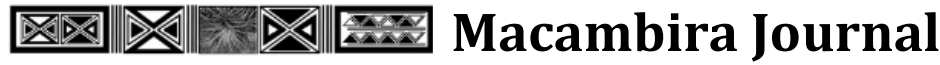

Revista Macambira Laboratory of Public Policies, Ruralities and Territorial Development (LaPPRuDes)

ISSN:2594-4754

ARTICLE

https://doi.org/10.35642/rm.v5i1.510

\section{The expansion of the Federal Institute of Santa Catarina from a social policy perspective}

Thiago Teixeira ${ }^{1 *}$, Kelly Gianezini ${ }^{2}$

\begin{abstract}
${ }^{1}$ University of the Extreme South of Santa Catarina (UNESC), Master of the Graduate Program in Socioeconomic Development (PPGDS) of UNESC.

https://orcid.org/0000-0003-2957$\underline{5302}$

${ }^{2}$ Permanent Professor of the Graduate Program in Socioeconomic Development (PPGDS) of UNESC, $\mathrm{PhD}$ in Education from UFRGS with phD internship at the University of California, Los Angeles (UCLA). http://orcid.org/0000-0002-8250$\underline{088 \mathrm{X}}$
\end{abstract}

${ }^{*}$ Corresponding author: thiago.teixeira@ifsc.edu.br

\begin{abstract}
:
This scientific paper discusses about the expansion of Federal Institutes of Education, Science and Technology, and it emphasizes on the process within the Federal Institute of Santa Catarina. This research aims to understand the process of expansion of the Federal Institute of Santa Catarina in a social policy perspective through bibliographic research about public policy, in order to establish a link among the expansion and the objectives of the Federal Institute of Education, Science and Technology of Santa Catarina. Public policies should reflect on social policy so they should be used as a tool that structures society and makes people's lives better. Some characteristics of the expansion of the Federal Network of Professional Education and Technology are noticed: expansion through interiorization, amplifying of professional education offer, concern about local productivity, and education focused on citizens. They can de associated to social public policies which implies that the connection among the community in which the campus is located, local productivity, and the Federal Institute is essential to understand the public policy present in the process of expansion, and also to achieve objectives.
\end{abstract}

Keywords: Federal Institute. Expansion. Public Policy. Socioeconomic Development.
MACAMBIRA JOURNAL

Federal Institute of Education, Science and Technology Baiano, campus Serrinha. Estrada Vicinal de Aparecida, s/n, Bairro Aparecida, Serrinha, Bahia, Brasil, CEP: 48700-000, sala 01, prédio acadêmico. 


\section{Introdução}

O Instituto Federal de Educação, Ciência e Tecnologia de Santa Catarina - IFSC teve sua origem na criação da Escola de Aprendizes Artífices, por meio do decreto n 7.566, de 23 de setembro de 1909, assinado pelo presidente Nilo Peçanha, que criou dezenove Escolas de Aprendizes Artífices, e essas foram distribuídas entre as Unidades Federativas que compunham o Brasil na época, sendo que a inauguração da escola ocorreu no ano seguinte.

Durante o século XX, além da sede de Florianópolis fundada em 1909, foram criadas as unidades de São José e Jaraguá do Sul, em 1988 e 1994, respectivamente. No século XXI, por meio de uma política pública do governo federal, que visava interiorizar o acesso à educação profissional pública, foram implantados 513 campi dos Institutos Federais pelo País, sendo que dezenove desses são do IFSC e foram distribuídos por todas as regiões do Estado da Santa Catarina, fazendo com que a Rede Federal de Educação Profissional e Tecnológica - RFEPT se tornasse uma das Instituições mais capilarizadas do Brasil.

Conforme dados extraídos da Plataforma Nilo Peçanha, em seu relatório publicado em 2020, em 2019 haviam 599 unidades de Institutos Federais no Brasil, sendo que dessas, 23 são campi pertencentes ao IFSC (MINISTÉRIO DA EDUCAÇÃO, 2020).

A política pública presente na expansão do IFSC por meio da interiorização vai além do que simplesmente qualificar mão de obra para o mercado. Ela tem um alcance mais amplo, pois não se trata apenas de uma política educacional. A implantação de campi em locais distantes da capital tem a missão de contribuir com o desenvolvimento socioeconômico da região.

O objetivo deste trabalho foi buscar compreender o processo de expansão do Instituto Federal de Santa Catarina numa perspectiva de política social, fazendo um levantamento bibliográfico sobre política pública, e por fim, estabelecendo uma relação dessas com a expansão e objetivos do Instituto Federal de Educação, Ciência e Tecnologia de Santa Catarina.

O artigo tem caráter exploratório e a pesquisa foi realizada por meio de um levantamento bibliográfico e documental. Gil (2010) afirma que a pesquisa bibliográfica é realizada a partir de materiais já publicados, que podem ser impressos, como: livros, revistas, dissertações, bem como publicações disponíveis em meio digitais e na internet; e a pesquisa documental baseia-se na análise de documentos, cuja produção tenha finalidade específica. Após leitura e estudo do referencial bibliográfico e documental, o autor compilou as informações encontradas de acordo com o fim proposto no trabalho.

Para melhor compreensão, foi dividido em três seções. A primeira seção aborda os conceitos de políticas públicas e sociais, enfatizando sua importância nas questões ligadas à inclusão social e ao acesso gratuito à educação. A segunda seção trata da expansão dos Institutos Federais pelo Brasil, com foco no processo ocorrido no IFSC, apresentando como esse se deu ao longo da história. Na última seção, as 
considerações finais sintetizarão as informações, os principais resultados e constatações encontradas na pesquisa.

\section{A política pública e social}

Num país continental como o Brasil, e com tamanha presença de desigualdades sociais e econômicas, o caráter das políticas públicas é ainda mais relevante, pois essas têm a função de criar mecanismos que tornem os direitos e serviços públicos acessíveis para um maior número de cidadãos.

A presença de políticas públicas ao redor do mundo é algo comum, tornando-se mais notável a partir da segunda metade do século passado. Conforme Souza (2006) a tradição europeia de estudos sobre políticas públicas a tratava como papel exclusivo do Estado, seus estudos estavam voltados a teorias explicativas da função do governo, sendo esse o produtor delas, porém nos Estados Unidos, os debates sobre o tema se iniciam na academia, relacionando-o com as ações governamentais, e mais adiante tornando-se uma subárea das ciências políticas.

O estudo das políticas públicas tem origem nos Estados Unidos no final do século XIX, defendendo a separação entre o político-decisão e o burocrático-executivo, em oposição a outro modelo caracterizado pela politização da administração e do amadorismo dos seus funcionários nomeados em função de suas capacidades políticas em detrimento da capacidade profissional. Este modelo de administração coincide com o êxito das empresas fordistas e os princípios do taylorismo, em um ambiente marcado pela confiança na capacidade da razão técnica para a solução dos problemas da sociedade. Mas foi com a Segunda Guerra Mundial que se aplicou a racionalidade científica e técnica para a resolução dos problemas sociais (FERNÁNDEZ, 2004).

As políticas públicas implementadas pelo Estado são ações que estiveram e estão presentes em vários países, que em dados momentos perceberam a necessidade de intervir, tendo em vista que o Estado é quem tem maior poder de tomar decisões que influenciem na vida das pessoas.

As políticas públicas são decisões governamentais, cujo resultado reflete na sociedade, de maneira focalizada ou universal, podendo ser específica de uma área ou grupo de interesse. "As políticas públicas repercutem na economia e nas sociedades, daí por que qualquer teoria da política pública precisa também explicar as inter-relações entre Estado, política, economia e sociedade” (SOUZA, 2006, p. 25). As políticas públicas adotadas pelo Estado na "relação, formada por princípios e valores, contribuiu com a sociedade, auxiliando muitos países a se consolidarem como democracias contemporâneas" (GIANEZINI et al., 2017). Essas ações estiveram presentes em momentos em que se percebeu a necessidade de intervir, tendo em vista que o Estado é quem tem maior poder de tomar decisões que influenciem na vida das pessoas. 
Um conceito para políticas públicas é apresentado por (SCHMIDT, 2018, p. 122), "políticas públicas são respostas do poder público a problemas políticos. Ou seja, as políticas designam iniciativas do Estado (governos e poderes públicos) para atender demandas sociais referentes a problemas políticos de ordem pública ou coletiva”. O governo, ao identificar determinados problemas que afetam a sociedade, busca a efetivação de iniciativas para resolver ou diminuir as situações apresentadas.

Nessa relação entre poder público, sociedade e política, faz-se necessário citar a importância dos movimentos sociais nas construções dessas conjunturas. Nesse sentido Gohn (2008) afirma que os movimentos sociais deixaram de ser somente operários. Movimentos identitários e culturais ganharam força nas últimas décadas. Esses movimentos reivindicam melhores condições de vida, como, por exemplo, acesso à educação. Algumas políticas públicas nascem desses questionamentos.

Ao serem analisadas a importância das políticas públicas, independente de serem econômicas, fiscais, educacionais ou mesmo com outro foco, é provável que se conclua que o importante é que elas reflitam no social, servindo como ferramenta para tornar melhor a vida das pessoas, ou seja, os impactos das políticas públicas devem ser o aumento da qualidade de vida dos cidadãos.

As ações das políticas sociais, bem como seus objetivos estão relacionadas com o "padrão de proteção social implementado pelo Estado, voltadas, em princípio, para a redistribuição dos benefícios sociais visando a diminuição das desigualdades estruturais produzidas pelo desenvolvimento socioeconômico.” (HÖFLING, 2001, p. 31)

Assim, a implementação de uma política social envolve vários fatores, desde conjunturas políticas de apoio e oposição, até influência de atores externos como agentes econômicos e/ou de mercado, assim, mesmo após analisar uma certa demanda ou carência e identificar uma maneira de agir no problema, o governo terá que buscar apoio para colocar em prática o plano de ação, pois apesar de parecer que políticas sociais agradam a todos, isso não ocorre no dia a dia do mundo político e na sociedade, afinal, grupos de interesses privados e individuais fazem parte de toda essa organização.

A política social nasce e se desenvolve através de relações de poder, como um processo complexo que inclui diferentes atores na relação entre Estado e sociedade, entre o público e o privado, envolve as correlações de forças entre capital e trabalho, e os princípios que regem os direitos de cidadania e suas condições reais de serem efetivados em uma sociabilidade burguesa (PAIVA, 2016).

No que diz respeito a políticas públicas no Brasil, essas relações de poder foram percebidas nas diferenças entre as agendas políticas dos governos da década de 1990 e posteriormente dos anos 2000. Num breve resumo, a política neoliberal da última década do século XX priorizava políticas sociais focalizadas, principalmente de combate à pobreza, e sem a intenção de alterar as relações estabelecidas na sociedade. No início do século XXI, num olhar mais progressista, percebe-se o aumento de investimentos em políticas públicas, num misto entre focalizadas e universais, visando alterar a realidade social (ALMEIDA, 2011). 
Uma das políticas públicas adotadas a partir da metade da década de 2000 foi a ampliação da RFEPT e, devido a algumas características, pode ser interpretada para além de uma política educacional, pois sua expansão se dá por meio da interiorização de seus campi, principalmente dos institutos federais, numa clara intenção de possibilitar aos cidadãos acesso à educação profissional e, consequentemente, promover o desenvolvimento socioeconômico dessas macrorregiões onde se instalaram as unidades. Faleiros (2004) analisa que as políticas sociais não são somente saúde, educação e habitação, e são concebidas com forte articulação política, social e econômica, sendo vistas como mecanismos de garantia do desenvolvimento socioeconômico e acesso a diretos pelos cidadãos, gerando assim bem-estar social.

Por mais que as políticas públicas de cunho educacional estejam ligadas ao processo de desenvolvimento social e econômico dos cidadãos, é necessário salientar que elas funcionam como base, e precisam ser trabalhadas em conjunto com outros segmentos da sociedade. Os setores políticos, econômicos, culturais e sociais precisam estar relacionados ao processo educacional com o propósito de diminuir as desigualdades existentes e promover desenvolvimento socioeconômico regional e consequentemente do País.

$\mathrm{Na}$ próxima seção serão analisadas as características dessa expansão, com foco na análise da interiorização dos campi do Instituto Federal de Santa Catarina.

\section{A expansão dos institutos federais numa perspectiva de política social}

A expansão da RFEPT, principalmente por meio do aumento do número de campi dos IFs, foi uma política pública nacional de caráter educacional e social, que almejava atender a uma demanda profissional que ocorria no País num momento de crescimento econômico, bem como a carência do acesso e oferta desse tipo de educação por todo o país.

No início do século XXI, com a retomada do crescimento econômico, o aumento dos investimentos nos chamados mercados emergentes e o avanço das novas tecnologias foram fatores que provocaram a necessidade de ampliação da formação de profissionais qualificados para atender a demanda de uma economia em expansão. Isso trouxe um novo dinamismo para a agenda pública da educação técnica e profissional, vivenciando um momento de transformação econômica, política e social, que seria ainda mais evidenciada em meados dos anos 2000 com a expansão da RFEPT (MACEDO, 2017).

O IFSC teve entre 2006 e 2014 o ápice de sua expansão e, nesse processo, a preocupação com o APL e a interiorização dos campi criados foram uma das marcas desse processo, caracterizando-o como uma política social, ao passo que aumentou a oferta de educação profissional gratuita em locais desassistidos dessa modalidade de educação, buscando assim para além de garantir o direito constitucional à educação, também intervir na realidade das regiões onde se instalou. 
A política pública presente na expansão do IFSC por meio da interiorização vai além de simplesmente qualificar mão de obra para o mercado, pois não se trata apenas de uma política educacional. A implantação de campi em locais distantes da capital tem a missão de contribuir para o desenvolvimento socioeconômico da região.

\section{A expansão do Instituto Federal de Santa Catarina}

O Instituto Federal de Educação, Ciência e Tecnologia de Santa Catarina (IFSC) teve sua origem a partir da criação da antiga EAA, por meio do Decreto n. 7.566, de 23 de setembro de 1909, assinado pelo então Presidente da República Nilo Peçanha. A inauguração da escola ocorreu no ano seguinte.

No século XXI, por meio de uma política pública do governo federal, que visava a interiorização e o acesso à educação profissional pública, foram criados 513 campi dos Institutos Federais dispersados pelas 27 unidades federativas do País.

No gráfico abaixo é possível acompanhar a expansão que ocorreu nesse período.

Figura 1 - Gráfico da Expansão da Rede Federal de Educação Profissional.

\section{Quantidade de Unidades}

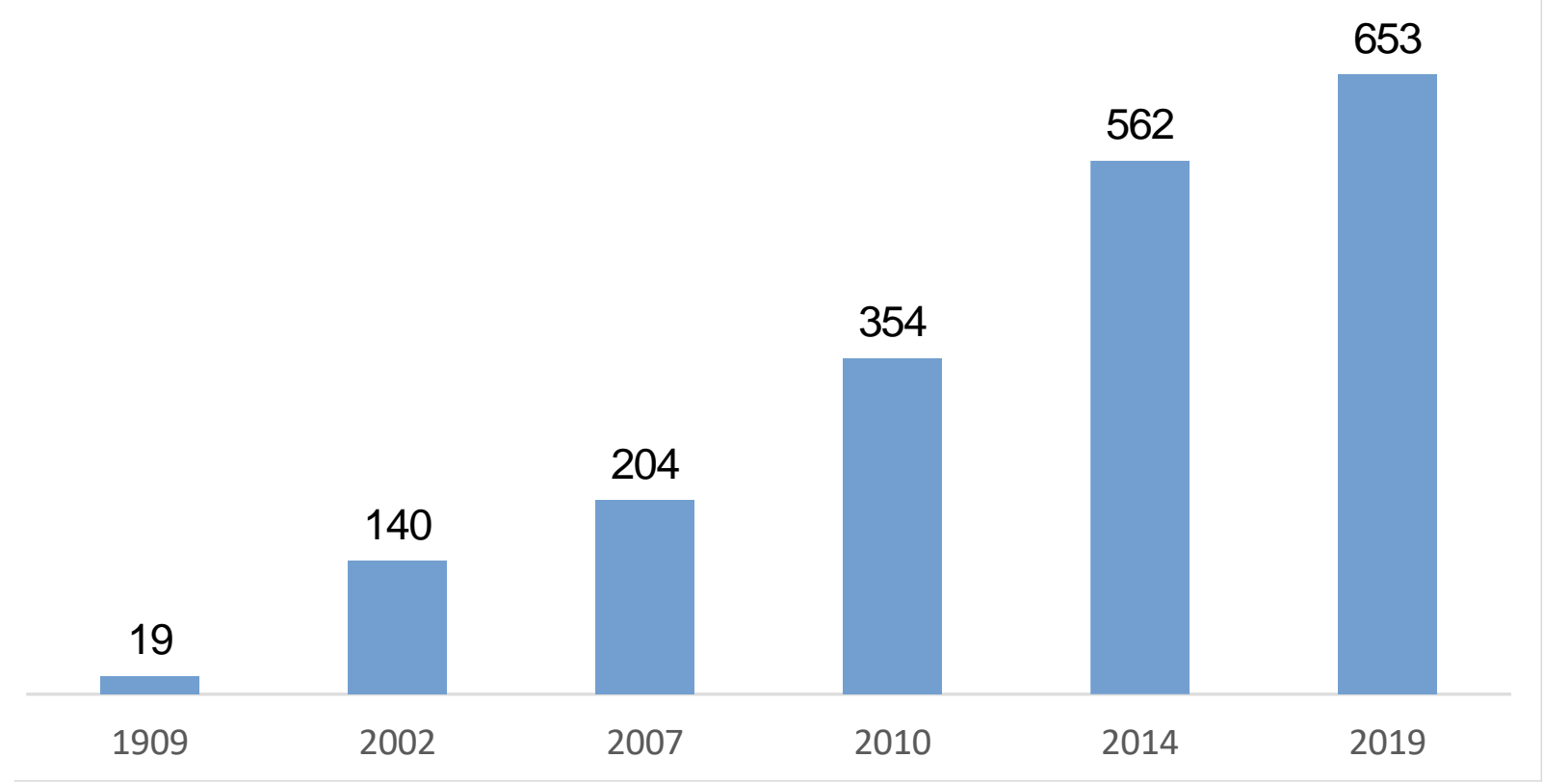

Elaborado pelo autor, 2020. Fonte: Plataforma Nilo Peçanha (MINISTÉRIO DA EDUCAÇÃO, 2020).

Em Santa Catarina foram instalados 20 novos campi do IFSC, os quais foram espalhados por todas as cinco regiões do estado de SC. Em 2019, o IFSC possuía 23 campi (MINISTÉRIO DA EDUCAÇÃO, 2020).

Durante o século XX, além da sede de Florianópolis fundada em 1909, foram criadas unidades nas cidades de São José e Jaraguá do Sul, em 1988 e 1994, respectivamente. Até 2005 o Instituto possuía três 
campi distribuídos pelo estado e, a partir de 2006, foram instaladas em todas as regiões do estado mais vinte unidades, totalizando os 23 campi que compõem a atual rede do IFSC.

O campus instalado na capital, cuja criação e inauguração ocorreram em 1909 e 1910, respectivamente, foi por muito tempo o único no estado, e devido a sua história e tamanho, possui protagonismo na rede. De acordo o Ministério da Educação (2020), o campus Florianópolis, que é o maior da instituição, representava em 2019 cerca de 16\% das matrículas do IFSC.

Os primeiros cursos oferecidos fora da capital ocorreram em 1988, na cidade de São José, numa parceria entre a prefeitura dessa cidade e o campus Florianópolis. Três anos mais tarde foi criada a unidade São José. Em 1994, foi inaugurada a terceira unidade do IFSC, na cidade de Jaraguá do Sul, no norte do estado, sendo considerada a primeira unidade localizada no interior.

Em 2005, por meio do plano de expansão da RFEPT, iniciou-se o projeto de interiorização, que teve como premissa oportunizar educação profissional para todas as regiões do País. Nessa fase no IFSC, foram criados quatro campi. Em 2006, inaugurou-se a unidade Florianópolis-Continente, instalada na parte continental da capital. Ainda nesse ano foram inauguradas as unidades Chapecó, no oeste, e a unidade Joinville, no norte do estado. Em 2008, pertencendo também a essa fase de expansão, foi inaugurado no sul do estado, o campus Araranguá.

O plano de expansão da RFEPT para cidades polo do território nacional estava integrado ao Plano de Desenvolvimento da Educação (PDE), e foi lançado pelo Ministério da Educação (MEC) como parte do Plano de Aceleração do Crescimento (PAC) do governo federal (GIANEZINI, 2018).

Dando continuidade ao projeto de expansão, em 2007 foi lançada a Fase II, que visava:

[...] a SETEC/MEC estabelece[u] como meta a criação, em quatro anos, de mais 150 novas instituições federais de educação tecnológica no marco do Plano de Expansão da Rede Federal de Educação Tecnológica. As instituições foram distribuídas nos 26 estados e no Distrito Federal, contemplando 150 municípios diferentes escolhidos pelo próprio MEC e mediante manifestação de interesse por parte das prefeituras municipais (BRASIL, 2018).

Entre 2009 e 2011 foram criados no IFSC mais doze campi, distribuídos por todo o estado. As cidades contempladas com unidades nessa fase II de expansão, seguidas pela região do estado foram: Em 2010: Canoinhas, norte; Criciúma, sul; Gaspar e Itajaí, ambos no vale do Itajaí; Lages, planalto serrano; Palhoça Bilíngue, na Região da Grande Florianópolis. Em 2011: Caçador e São Miguel do Oeste, oeste; Urupema, planalto serrano, Garopaba, sul. Ainda foram federalizados em 2010 os campi Geraldo Werninghaus (Jaraguá do Sul), norte, e Xanxerê, oeste.

Em 2011, foi lançado o plano de expansão - fase III, e o IFSC foi contemplado com a criação dos campi Tubarão, no sul, e São Lourenço do Oeste, ambos inaugurados em 2014. Em 2015 foi inaugurado o campus São Carlos, no oeste. 
Sua terceira fase [...] estabeleceu um projeto de criação de 208 novas unidades até 2014, permanecendo o propósito de superação das desigualdades regionais e na viabilização das condições para acesso a cursos de formação profissional e tecnológica como ferramenta para melhoria de vida da população (BRASIL, 2018).

Na segunda década do século XXI, o IFSC criou o Centro de Referência em Formação e Educação a Distância (CERFEAD), que consiste numa diretoria com status de campus com responsabilidade na formação de servidores e educação a distância na instituição.

No gráfico a seguir pode ser visualizada a expansão ocorrida no IFSC, com destaque ao período compreendido no século XXI.

Figura 2 - Gráfico da expansão do Instituto Federal de Santa Catarina

\section{Quantidade de unidades instaladas}

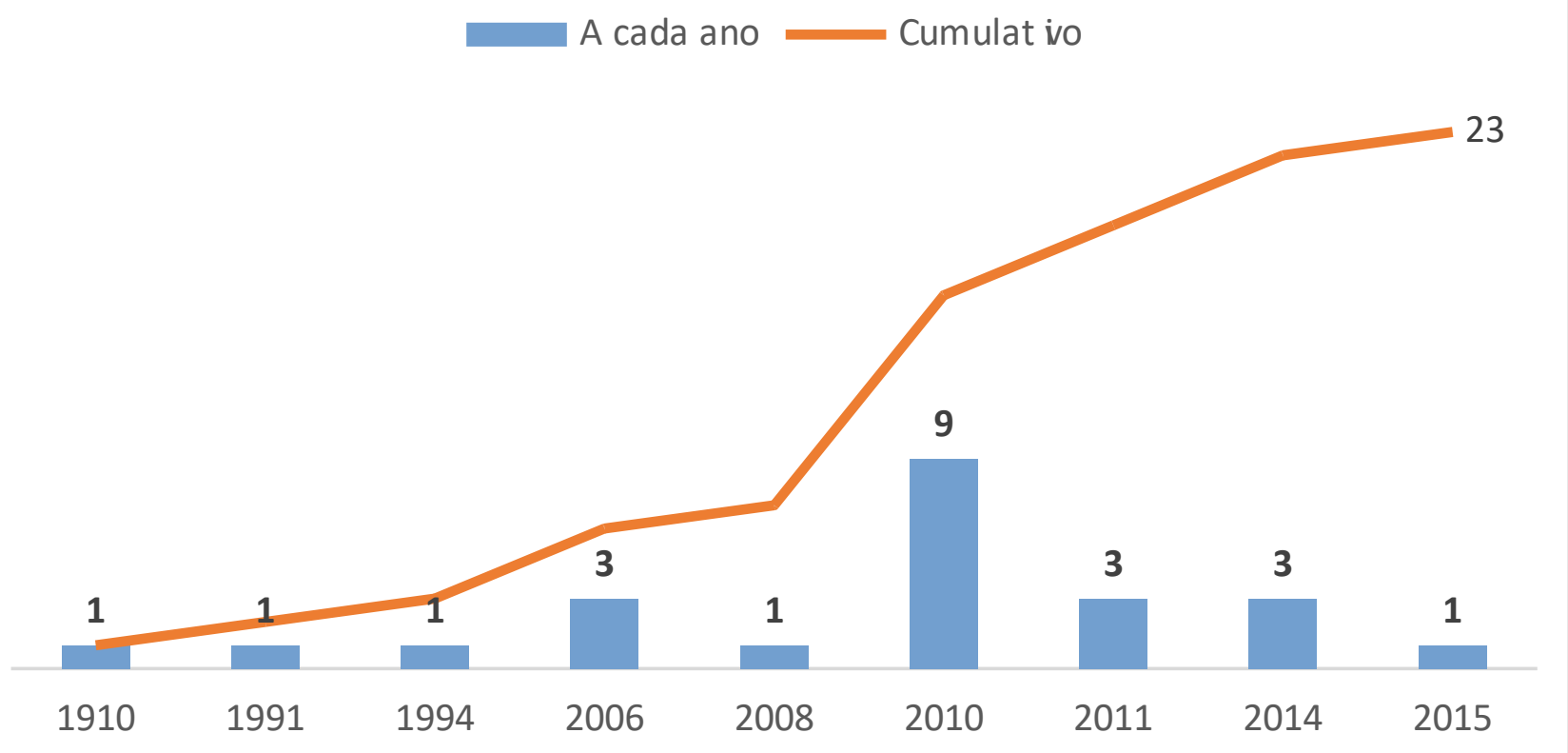

Elaborado pelo autor, 2020. Fonte: Plataforma Nilo Peçanha (MINISTÉRIO DA EDUCAÇÃO, 2020).

Considerando todos os seus campi, o IFSC contabiliza atualmente 23 unidades de ensino, presentes em todas as regiões do estado, que em 2019 somaram mais de quarenta mil matrículas (MINISTÉRIO DA EDUCAÇÃO, 2020). Dos 20 campi instalados a partir de 2006, dezessete estão localizados no interior, distribuídos entre todas as regiões. Somente os campi Florianópolis-Continente, Palhoça e CERFEAD foram instalados na Região da Grande Florianópolis, reforçando a tese de que a expansão se deu por meio da interiorização.

Na Figura 3, é apresentada a localização dos campi do IFSC, indicando a região do estado, bem como o ano de implantação. 
Figura 3 - Distribuição dos Campi do Instituto Federal de Santa Catarina.

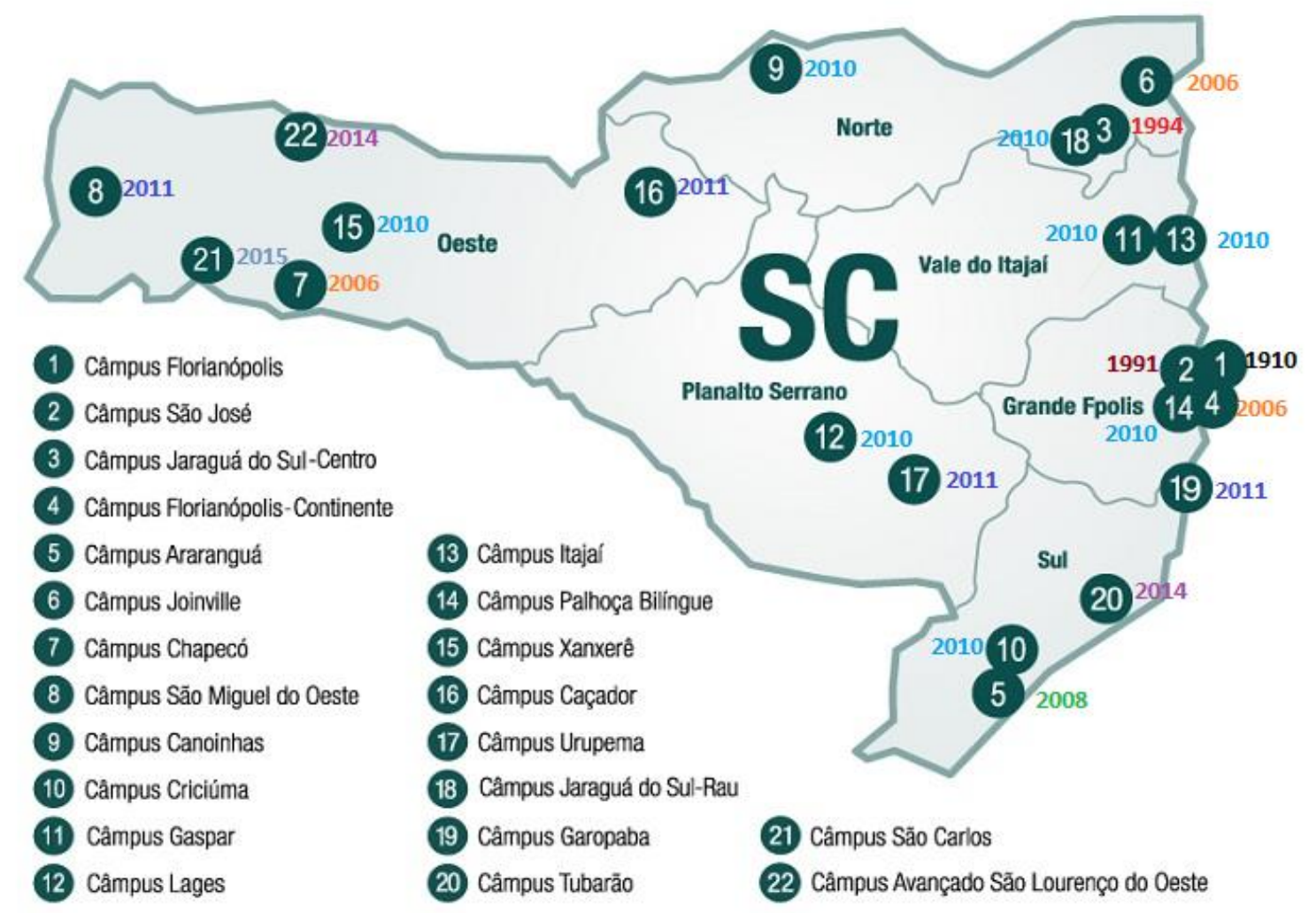

Elaborado pelo autor, 2020. Fonte: Site do IFSC (BRASIL, 2018b).

No trabalho de Silva (2015), no qual o processo de expansão da RFEPT foi analisado nos três estados do sul do País (RS, SC e PR) entre 2005 e 2015, o autor reforça a importância da interiorização dos campi, bem como o aumento da população atendida pela rede. Silva (2015) ainda afirma que Santa Catarina foi o estado do Sul com melhor grau de interiorização e que a implantação de novos campi alcançou todas as mesorregiões do estado.

\section{Análise da expansão do Instituto Federal de Santa Catarina numa perspectiva de política social}

Analisando os conceitos de políticas públicas, observa-se que essas estão normalmente ligadas a ações governamentais direcionadas a um determinado grupo, ou para o atendimento de certas necessidades. Na lei que criou a RFEPT, pode-se encontrar explicitamente características de política pública, claramente inclinadas para um olhar social.

Para exemplificar o exposto acima, é possível citar um dos objetivos dos IFs presentes na lei que é “estimular e apoiar processos educativos que levem à geração de trabalho e renda e à emancipação do cidadão na perspectiva do desenvolvimento socioeconômico local e regional” (BRASIL, 2008, p. 4). Há no texto legal a indicação de que o processo de educação seja voltado ao trabalho, mas numa perspectiva 
de formação ao cidadão, em que a geração de renda contribua para o desenvolvimento social e econômico das pessoas, refletindo nas questões regionais e locais.

No processo de ampliação da capacidade de atendimento dos IFs dentro do território nacional, Pacheco (2010) analisa que a educação deve ser compreendida como uma política social capaz de emancipar o cidadão, e sua força deve constantemente ser renovada por meio de projetos estratégicos que busquem a construção de uma sociedade fundada na igualdade política, econômica e social, assim ele destaca a importância da interiorização da RFEPT, enfatizando a questão de cada vez se facilitar mais o acesso a essas instituições.

O projeto de expansão dos IFs, numa perspectiva progressista do governo Lula, foi uma política pública para além da educação, pois ao levar essas instituições para várias regiões do País, ficou clara a intenção de intervir na realidade local, principalmente pelo acesso gratuito a uma educação profissional pública e de qualidade. A interiorização dos campi dos IFs permitiu a milhares de cidadãos o acesso a um serviço que, por muito tempo, só existiu nas capitais, e isso contribuiu para a formação de pessoas que residiam fora das capitais. Entre os objetivos dessa ação é possível citar: 1- fomentar o desenvolvimento regional, estimulando a permanência de profissionais qualificados no interior do Brasil; 2- democratizar o acesso de vagas na educação profissional e tecnológica; 3- potencializar a função social como expressão das políticas do governo federal na superação da miséria e na redução das iniquidades sociais e territoriais (SILVA; TERRA, 2013).

Com a interiorização dos campi e a possibilidade de capacitação próximo de casa, esses estudantes após formados tendem a ali permanecerem e contribuírem para o desenvolvimento local e regional. Esse fato contribui para combater a migração de pessoas que se deslocavam do interior para estudarem na capital, e após concluírem a capacitação não retornavam a suas cidades de origem.

Atuando em todos os níveis de educação profissional, e considerando a autonomia prescrita na lei, os IFs buscam se adequar às realidades das regiões em que estão inseridos, atuando de forma ágil e eficaz nas demandas existentes, com foco no desenvolvimento socioeconômico sustentável, com vistas à inclusão social (MACEDO, 2017).

Outro aspecto relacionado à expansão é a importância dada ao APL. Para Silva e Terra (2013), APLs englobam a ideia de redes, pois formam um sistema localizado de agentes econômicos, políticos e sociais ligados a um mesmo setor ou atividade econômica, acarretando a concretização de vínculos produtivos e institucionais entre si. Assim, proporcionam aos produtores um conjunto de benefícios relacionados com a aglomeração das empresas.

$\mathrm{Na}$ escolha dos cursos que seriam ofertados nos campi novos, foi direcionada atenção ao APL, envolvendo agentes da sociedade, tecendo uma rede de comunicação que proporcionaria o alcance do objetivo de desenvolver social e economicamente a região. Essa preocupação com o APL é mais um 
indicativo de que a instalação de um campus em determinado local visa, para além da formação do cidadão, contribuir para a melhoria da realidade da região (SILVA, 2017). A ligação entre a comunidade, o APL e o instituto é condição sine qua non para a compreensão da política pública, bem como para sua eficiência.

É importante frisar que não bastava criar novos campi, pois para a consolidação dos objetivos da expansão da RFEPT, esses deveriam ser instalados no interior, atendendo assim o chamado para intervirem no desenvolvimento local e regional, e tornando mais justa e ampliada a oferta de educação profissional gratuita.

Para melhor compreensão do quanto a política de expansão influenciou nas regiões onde se instalaram os campi, no que diz respeito ao número de pessoas que passaram a ter acesso a esse tipo de educação, pode-se analisar os dados relativos a 2019 extraídos da plataforma Nilo Peçanha na Tabela 1:

Tabela 1 - Número de Matrículas registradas no Instituto Federal de Santa Catarina.

\begin{tabular}{lcccc}
\hline Local & \multicolumn{2}{c}{ Matrículas } & \multicolumn{2}{c}{ Cursos } \\
\hline Capital & 12.014 & $26,8 \%$ & 128 & $22,3 \%$ \\
Interior & 28.441 & $63,5 \%$ & 438 & $76,4 \%$ \\
CERFEAD & 4.269 & $9,7 \%$ & 7 & $1,3 \%$ \\
\hline Total & $\mathbf{4 4 . 7 2 4}$ & $\mathbf{1 0 0 \%}$ & $\mathbf{5 7 3}$ & $\mathbf{1 0 0 \%}$
\end{tabular}

Elaborado pelo autor, 2020. Fonte: Plataforma Nilo Peçanha (MINISTÉRIO DA EDUCAÇÃO, 2020).

Os dados referentes à capital englobam os campi Florianópolis, Florianópolis - Continente e o São José. O interior, por sua vez, é representado pelos outros 19 campi da rede. O CERFEAD, por tratar-se de educação a distância, foi analisado de forma separada, uma vez que atende estudantes de outras cidades, embora a sede encontre-se na capital.

É perceptível o impacto da expansão no número de estudantes, sendo que mais de 28 mil desses encontram-se em cidades do interior. Para esses estudantes, o direito a uma educação pública de qualidade, e sobretudo profissional, estava renegado na maioria dos casos. Mesmo que uma minoria pudesse se deslocar para estudar na capital, há a questão de qualificar as pessoas nos locais onde residem para ali contribuírem com o desenvolvimento.

A criação de instituições de ensino superior e técnico em cidades do interior foi uma estratégia para fomentar desenvolvimento social e econômico em localidades menos desenvolvidas do Brasil, dando um tratamento mais equitativo aos cidadãos, assegurando a estes uma formação profissional que melhor se adapte a sua região (GIANEZINI, 2018).

A expansão por meio da interiorização, a ampliação da oferta de educação profissional, a preocupação com o APL e a formação focada no cidadão são características da expansão da RFEPT que 
podem ser relacionadas com as políticas de cunho social, cujo principal objetivo é garantir aos cidadãos o acesso a direitos, contribuindo para o melhoramento da qualidade de vida.

\section{Conclusão}

Todos os processos que envolveram a criação da Escola de Aprendizes Artífices, as transformações ocorridas nessas escolas ao longo do século, bem como a expansão dos Institutos Federais em meados da década de 2000, mostram que esses fatos sempre tiveram uma ligação estreita com as questões sociais, políticas e econômicas do País.

A expansão da Rede Federal de Educação Profissional e Tecnológica, principalmente por meio do aumento do número de campi dos Institutos Federais, foi uma política pública de caráter educacional e social, que visava atender a uma demanda profissional que ocorria no País num momento de crescimento econômico, bem como a carência do acesso e oferta desse tipo de educação por todo o País.

O IFSC teve entre 2006 e 2014 o ápice de sua expansão, e conforme analisado, a interiorização dos campi implantados foi uma das marcas desse processo, caracterizando-o como uma política social, ao passo que aumentou a oferta de educação profissional gratuita a locais desassistidos dessa modalidade educação, buscando assim para além de garantir o direito constitucional à educação, também intervir na realidade das regiões onde se instalou.

A preocupação com o APL, bem como com a elevação da escolarização e formação científica e tecnológica do cidadão, reforçam a ideia de cunho social presente na expansão, fato esse que foi confirmado no texto da Lei $\mathrm{n}^{\circ}$ 11.982, de 29 de dezembro de 2008 que instituiu a Rede Federal de Educação Profissional, Científica e Tecnológica e criou os Institutos Federais de Educação, Ciência e Tecnologia.

Ao se instalar em todas mesorregiões do Estado, o IFSC contribuiu para tornar mais ampla e justa a oferta de educação profissional, possibilitando que as pessoas se capacitassem em suas próprias regiões, estimulando a permanência desses profissionais no interior do País.

Os critérios presentes na forma como ocorreu, bem como os objetivos e finalidades dispostas na Lei 11.982, que criou a RFEPT, indicam que o processo de expansão ocorrido no IFSC pode ser compreendido como uma política pública social.

\section{Referências}

ALMEIDA, Luana Costa. Políticas sociais: focalizadas ou universalistas. É esta a questão? Revista Acadêmico, Maringá, v. 123, n. 11, p.145-151, ago. 2011. 
BRASIL. Lei $\mathbf{n}^{\circ}$ 11.982, de 29 de dezembro de 2008. Institui a Rede Federal de Educação Profissional, Científica e Tecnológica, cria Os Institutos Federais de Educação, Ciência e Tecnologia, e dá outras providências. Brasília, 2008. Disponível em: http://www.planalto.gov.br/ccivil_03/_ato20072010/2008/lei/111892.htm. Acesso em: 09 dez. 2019.

BRASIL. Instituto Federal de Santa Catarina. Ministério da Educação. Câmpus. 2018b. Disponível em: https://www.ifsc.edu.br/campus. Acesso em: 23 nov. 2020.

BRASIL. Ministério da Educação. Expansão da Rede Federal. 2018. Disponível em: http://portal.mec.gov.br/setec-programas-e-acoes/expansao-da-rede-federal. Acesso em: 18 nov. 2019.

FALEIROS, Vicente de Paula. O que é política social. São Paulo: Brasiliense, 2004.

FERNÁNDEZ, A. Las políticas públicas. p. 460-482. In: BADIA, M. C. (Editor). Manual de ciência política. 2. ed. Madrid: Tecnos, 2004.

GIANEZINI, K. As transformações e o processo de expansão da educação superior em Mato Grosso. Cuiabá: EdUFMT, 2018.

GIANEZINI, K. et al. Políticas Públicas: Definições, processos e constructos do século XXI. Revista de Políticas Públicas, São Luiz, v. 21, n. 2, p. 1065-1084, jul./ dez. 2017.

GIL, Antônio Carlos. Como elaborar projeto de pesquisa. 5. ed. São Paulo: Atlas, 2010.

GOHN, M. da G. Abordagens Teóricas no Estudo dos Movimentos Sociais na América latina. Caderno CRH, Salvador, v. 21, n. 54, p. 439-455, set./dez. 2008.

HÖFLING, Eloisa de Mattos. Estado e políticas (públicas) sociais. Cadernos Cedes, Campinas, v. 55, n. 21, p.30-41, nov. 2001.

MACEDO, P. C. S. Educação profissional e desenvolvimento territorial: expansão dos Institutos Federais de Educação, Ciência e Tecnologia. Revista Brasileira da Educação Profissional e Tecnológica, Natal, v. 2, n. 13, p. 94-106, jul./dez. 2017.

MINISTÉRIO DA EDUCAÇÃO (MEC). Plataforma Nilo Peçanha: Resultados 2020. Disponível em: http://plataformanilopecanha.mec.gov.br/2020.html. Acesso em: 18 ago. 2020.

PACHECO, Eliezer Moreira. Os Institutos Federais: uma revolução na educação profissional e tecnológica. Natal: IFRN, 2010.

PAIVA, Ariane Rego de. Análise e avaliação de políticas sociais: algumas perspectivas do debate atual. O Social em Questão, Rio de Janeiro, v. 36, n. 19, p.19-38, jul./dez. 2016.

SCHMIDT, J. P. Para estudar políticas públicas: aspectos conceituais, metodológicos e abordagens teóricas. Revista do Direito, Santa Cruz do Sul, v. 3, n. 56, p. 119-149, set./dez 2018.

SILVA, Arthur Resende da; TERRA, Denise Cunha Tavares. A expansão dos Institutos Federais de Educação, Ciência e Tecnologia e os desafios na contribuição para o desenvolvimento local e regional. In: I Seminário Nacional de Planejamento e Desenvolvimento, 2013, Curitiba. I Seminário Nacional de Planejamento e Desenvolvimento. Curitiba: Universidade Federal Tecnológica do Paraná, 2013. 
SILVA, Jesué Graciliano da. A Expansão da rede federal de educação profissional, científica e tecnológica na região sul do Brasil. In: ENCONTRO NACIONAL DA ANPEGE, 11, 2015, Presidente Prudente. Anais [...] . Dourados: Ufgd, 2015. p. 11150-11162.

SOUZA, Celina. Políticas Públicas: uma revisão da literatura. Sociologias, Porto Alegre, Ano 8, n. 16, p. 20-45, jul./dez. 2006.

\begin{tabular}{|c|c|}
\hline Informações do Artigo & Article Information \\
\hline Recebido em: 28/11/2020 & Received on: $28 / 11 / 2020$ \\
\hline Aceito em: 29/03/2021 & Accepted in: 29/03/2021 \\
\hline Publicado em: 15/04/2021 & Published on: 15/04/2021 \\
\hline $\begin{array}{l}\text { Conflitos de Interesse: Os autores declaram não } \\
\text { haver quaisquer conflitos de interesse referente a } \\
\text { este artigo. }\end{array}$ & Conflict of Interest: No reported. \\
\hline Como citar este artigo & How to cite this article \\
\hline $\begin{array}{l}\text { Teixeira, T.; Gianezini, K. (2021). A expansão do } \\
\text { Instituto Federal de Santa Catarina numa } \\
\text { perspectiva de política social. Revista Macambira, } \\
5(1) \text {, } 051002 . \\
\text { https://doi.org/10.35642/rm.v5i1.510. } \\
\\
\text { Licença: }\end{array}$ & $\begin{array}{l}\text { Teixeira, T.; Gianezini, K. (2021). The expansion } \\
\text { of the Federal Institute of Santa Catarina from a } \\
\text { social policy perspective. Revista Macambira, } \\
5(1) \text {, } 051002 . \\
\text { https://doi.org/10.35642/rm.v5i1.510. } \\
\text { License: }\end{array}$ \\
\hline c) (†)(5) & (c) $(1)$ () \\
\hline $\begin{array}{l}\text { Este trabalho está licenciado sob uma Licença } \\
\text { Internacional Creative Commons Attribution- } \\
\text { NonCommercial-ShareAlike } 4.0 \text { International . }\end{array}$ & $\begin{array}{l}\text { This work is licensed under a Creative Commons } \\
\text { Attribution-NonCommercial-ShareAlike } \\
\text { International License. }\end{array}$ \\
\hline
\end{tabular}

